\title{
Interactions of Indomethacin with Functionalized Rhombellanes - a Molecular Docking Study
}

\author{
Raluca Pop, ${ }^{1, *}$ Dušanka Janežič 2
}

1 Faculty of Pharmacy, University of Medicine and Pharmacy “Victor Babeş” Timisoara, Eftimie Murgu Square 2, 300041 Timişoara, Romania
2 Faculty of Mathematics, Natural Sciences and Information Technologies, University of Primorska, Koper, Slovenia
${ }^{*}$ Corresponding author's e-mail address: pop.raluca@umft.ro

RECEIVED: October 17, 2019 * REVISED: January 20, 2020 * ACCEPTED: January 20, 2020

\begin{abstract}
The specific properties of carbon-based nanomaterials like fullerenes and graphenes have attracted a continuous interest for their possible use as drug carriers. The functionalization of these nanomaterials can lead to the variation or improvement of the required properties, in order to lead to the design of the most suitable compounds within a specific field. In this regard, the possible use of a new class of nanostructures -the rhombellanes- as nanocarriers is investigated. The aim of the paper is to study the interactions of indomethacin and four analogues with anti-inflammatory activity on 13 rhombellanes (three of them with a hyper-adamantane motif, Ada-rbl, three cube-rhombellane homeomorphs, C-rbl, and seven cube-rhombellane-ether/amine structures). Five compounds with anti-inflammatory activity have been docked to the surface of the rhombellanes; comparisons with the results obtained for fullerene $\mathrm{C}_{60}$ have been performed. The best binding affinities for the indomethacin and its derivatives have been obtained for two types of rhombellanes, Ada-rbl and C-rbl. The indomethacin analogue 14 shows an increased binding affinity for $\mathrm{C}$-rbl.420, similar to the value obtained for $\mathrm{C}_{60}$. Best results have been obtained for rhombellane derivatives characterized by smaller HOMO-LUMO gaps.
\end{abstract}

Keywords: binding energy, molecular docking, indomethacin, fullerene, rhombellane.

\section{INTRODUCTION}

NFLAMMATION is a defensive response of the body that causes physiological adaptations in order to minimize tissue damage and eliminate pathogenic infections. Such mechanisms involve a complex series of cellular phenomena, including dilatation of arterioles and capillaries with increased vascular permeability, as well as migration of leukocytes into the inflamed area. Chronic inflammation is an important factor contributing to morbidity and mortality, and may lead to diseases such as arthritis, osteoarthritis, retinitis, multiple sclerosis, psoriasis, and atherosclerosis. ${ }^{[1-3]}$

In this regard, some of the most commonly used classes of compounds are non-steroidal anti-inflammatory drugs; an important representative of this class of compounds being the indomethacin. The basic structure of the indomethacin consists of an indole and a benzene ring, linked by a carbonyl group.
Non-steroidal anti-inflammatory drugs (NSAIDs) are widely used to treat minor pain and manage edema and tissue damage that may occur in arthritis. In addition to antiinflammatory activity, a large number of compounds in this class also have antipyretic activity and are used in the treatment of fever. In most cases, the therapeutic action of these compounds is manifested by the inhibition of prostaglandin biosynthesis. ${ }^{[4-6]}$

As a result, NSAIDs are characterized by the presence of a carboxyl group, being relatively strong organic acids; their lipophilic character may vary due to the presence of the different substituents attached to the phenyl ring. ${ }^{[7]}$ In silico evaluation of the anti-inflammatory effects of indole derivatives like isoindoline, ${ }^{[8]}$ indomethacin-based analogs ${ }^{[9]}$ and indole- $\mathrm{N}$-acyl hydrazones ${ }^{[10]}$ outlined their potential as selective COX- 2 inhibitors.

Within the last years, nanomaterials have become ubiquitous in fields that vary from IT (Information 


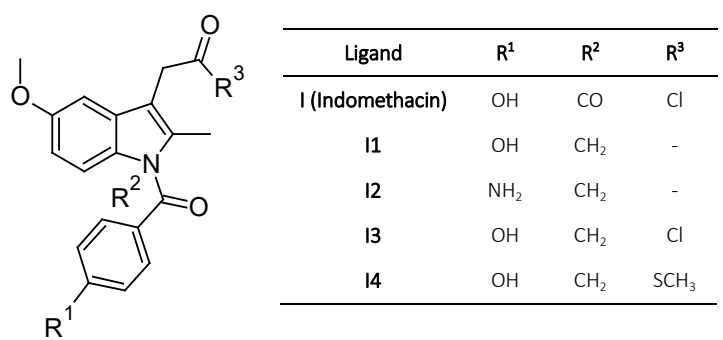

Figure 1. General structure of the investigated compounds.

Technology) and electronic industries to chemistry and environmental applications. Due to their unique characteristics like small sizes, various surfaces and adjustable properties, they gained an important role in every industry. The medicine field is not an exception to this increased interest for applications of nanomaterials; there are various studies that outline the possibility of using them as drug carriers, for medical imaging and disease diagnoses. ${ }^{[11-13]}$

The present paper aims to investigate the interactions between some anti-inflammatory bioactive compounds (indomethacin and four derivatives) and a new class of nanostructures, the rhombellanes. The rhombellane structures were proposed and defined by Diudea; ${ }^{[14,15]}$ all their strong rings are rhombs/squares and they can be considered functionalized derivatives of bicyclo[1.1.1]pentane. Detailed information regarding their construction is given elsewhere, ${ }^{[14]}$ and the structural specifications of the 13 rhombellanes that are investigated within the present study are presented in Table 1. (The structures of the 13 rhombellanes are included in the supplementary file of the paper).

As mentioned before, the investigated ligands are the indomethacin and four derivatives where the $\mathrm{N}$-benzoyl moiety has been replaced by N-benzyl.[16] According to literature data, ${ }^{[16]} \mathrm{N}$-benzyl analogues have been found to exhibit an enhanced biologic activity (compared to the $\mathrm{N}$ benzoyl ones). This way, the main structural change of the indomethacin derivatives consists in the replacement of the linking $\mathrm{C}=\mathrm{O}$ group with a $\mathrm{CH}_{2}$ one, together with the presence/absence of the substituents on the phenyl cycle. The general structure of the investigated ligands ${ }^{[16]}$ is given in Figure 1.

\section{MATERIALS AND METHOD}

This paper continues the exploring of bioactive molecules by molecular docking and QSAR methods developed by one of us (D. J) together with Topo Group Cluj. The method uses the binding affinities collected by a molecular docking procedure and submit them to an algorithm using a hypermolecule that mimics the receptor and takes account of the orientation of ligands with respect to the hypermolecule; ${ }^{[17-20]}$ fragment mass and/or partial charges are used to quantify the ligand superposition over the hypermolecule and perform the QSAR models. The abovementioned docking methodology ${ }^{[18-20]}$ and AutoDock Vina software ${ }^{[21]}$ have been successfully employed for analyzing the interactions of 40 caffeine derivatives with poly(A)RNA polymerase protein Cid1. ${ }^{[19]}$ Another study ${ }^{[18]}$ dealt with the development of a new knowledge-based method that identifies the possible biosiosteric replacements. AutoDock Vina ${ }^{[21]}$ was employed for the evaluation of the newly obtained compound, which obtained a similar score when compared to the original compound. Also, the most prominent non-covalent interactions among some new synthesized Schiff bases, A-DNA and B-DNA have been identified throughout a docking study performed with AutoDock Vina ${ }^{[2]}$. The structures of the indomethacin and its analogues have been optimized, the vibrational analysis proving that true minima have been obtained. For the rhombellane structures, a single point computation has been performed. The energies of the HOMO and LUMO orbitals, the polarizability, ${ }^{[22,23]}$ magnetizability ${ }^{[24]}$ and the dipole moment have been computed by means of ADF software, ${ }^{[25-27]}$ at BLYP/TZP level of theory. ${ }^{[28]}$ The descriptors of the molecular shape ${ }^{[29]}$ (ovality, solvent accessible surface, Connolly solvent excluded volume) and the partition coefficient logP have been obtained with Chem3D software. Multiwfn 3.3.7[30] has been used for the graphical representation of the HOMO orbitals, while Autodock $V_{i n a}{ }^{[21]}$ has been employed for the docking simulation. The binding constant $K_{\mathrm{B}}$ has been calculated with the following equation:

$$
K_{B}=e^{-\frac{\Delta G_{B}}{R T}}
$$

where $\Delta G_{B}$ is the binding affinity $\left(\mathrm{J} \mathrm{mol}{ }^{-1}\right), R$ - gas constant $\left(\mathrm{J} \mathrm{mol} \mathrm{K}^{-1}\right), \mathrm{T}$ - temperature $(298 \mathrm{~K})$.

\section{RESULTS AND DISCUSSION}

\section{Ligand Characterization}

Prior to the docking studies, a number of parameters including the molecular shape descriptors, magnetic properties, hydrophobic/hydrophilic character and frontier molecular energies have been computed.

The frontier molecular orbitals HOMO and LUMO play an important role in determining the reactivity of the various regions of the molecules. In this regard, detailed information regarding their energy and distribution can also be useful in docking studies, where the interactions between small compounds and proteins are investigated. 


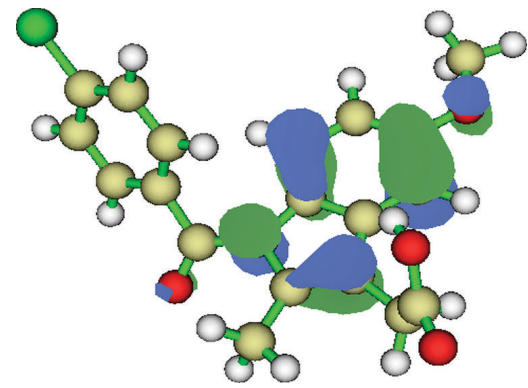

Figure 2. Localization of the HOMO orbitals for indomethacin.

Table 1. Frontier molecular orbitals energies and computed $\mathrm{HL}$ gap (BLYP/TZP) of the investigated indomethacin derivatives.

\begin{tabular}{cccc}
\hline Ligands & Eномо $/ \mathrm{eV}$ & ELumo $/ \mathrm{eV}$ & $\mathrm{HL}$ gap / eV \\
\hline I & -8.512 & 1.263 & 9.775 \\
I1 & -7.947 & 1.304 & 9.251 \\
I2 & -7.731 & 1.408 & 9.139 \\
I4 & -8.056 & 1.199 & 9.255 \\
\hline
\end{tabular}

The results depicted in Table 1 outline a small decrease of the HOMO energy and of the overall HOMOLUMO gap together with the replacement of the carbonyl group (R2) between the indole and benzene rings with methylene; the lowest stability has been predicted for the indomethacin derivative 12 , characterized by the presence of $\mathrm{CONH}_{2}$ group and the lack of the chlorine on the phenyl cycle.

Concerning the localization of the frontier molecular orbitals of indomethacin, the HOMO orbital (for indomethacin) is located on the indole skeleton and, to a lesser extent, on the linking group ( $\mathrm{CO}$ ) between the indole ring and the benzene ring. (Figure 2; graphical representation of the HOMO orbitals for ligands I1-I4 is included within the Supplementary Material).
The absence of the $\mathrm{C}=\mathrm{O}$ group, which provides an extended conjugation for indomethacin and which has been replaced by a methylene group in derivatives 11-14, leads to a change in the distribution of molecular orbitals. Thus, in the case of the four analogs of indomethacin, the LUMOs mainly appear on the C-atoms of the indole cycle and on the functional groups $\mathrm{COR}\left(\mathrm{COOH}\right.$ and $\mathrm{CONH}_{2}$, respectively). The replacement of the $\mathrm{COOH}$ group with $\mathrm{CONH}_{2}$ or the absence of $\mathrm{Cl}$ in position 4 of the benzene skeleton does not affect the distribution of orbitals.

Other parameters that can influence the binding affinity of molecules are the ones related to the shape, hydrophilic or hydrophobic character, and the number of hydrogen bond acceptors or donors. An accurate description of the molecular shape leads to valuable information regarding the prediction of reactivity and molecular interactions. Ovality is the parameter that characterizes the deviation from the spherical shape to an oval one; in other words, ovality represents the difference between the largest and smallest outer diameter on a cross-section of the compound. ${ }^{[24]}$ The solvent accessible surface is the surface area of a bioactive compound that is accessible to a solvent. It is frequently used for the computation of the free energy required to transfer a compound between polar/non-polar environments. On the other hand, Connolly solvent excluded volume is the volume contained within the contact molecular surface. ${ }^{[24]}$

According to the obtained results, all the investigated ligands are characterized by an identical number of hydrogen bond acceptors and donors, and similar values for parameters like ovality and polarizability. The presence of a bulky group in $14\left(\mathrm{SCH}_{3}\right)$ leads to slightly increased values of the shape parameters (compared to compounds I-13). The replacement of the carbonyl group of indomethacin (I) with a methylene one (I3) influences only the dipole moment value. The molecular shape descriptors, the polarizability and the hydrophobic character outlined by the $\log P$ values are almost identical for ligands I and I3. As regards the $I 1$ ligand, the replacement of the $C=0$ group and the removal of the $\mathrm{Cl}$ atom lead to a diminished solvent

Table 2. Global parameters of the ligands: solvent accessible area, solvent excluded volume, ovality, partition coefficient, dipole moment and the number of hydrogen bond acceptors and donors.

\begin{tabular}{|c|c|c|c|c|c|c|c|}
\hline Ligands & Solvent accessible area / $\AA^{2}$ & $\begin{array}{c}\text { Connolly Solvent } \\
\text { Excluded Volume } / \AA^{3}\end{array}$ & Ovality & $\log P$ & Dipole moment / D & $\begin{array}{l}\text { HBA (Hydrogen } \\
\text { bond acceptors) }\end{array}$ & $\begin{array}{c}\text { HBD (Hydrogen } \\
\text { bond donors) }\end{array}$ \\
\hline 1 & 583.24 & 278.04 & 1.497 & 4.180 & 2.519 & 3 & 1 \\
\hline 11 & 555.71 & 266.55 & 1.463 & 3.894 & 2.503 & 3 & 1 \\
\hline 12 & 563.91 & 270.96 & 1.472 & 2.934 & 4.914 & 3 & 1 \\
\hline 13 & 580.82 & 281.09 & 1.485 & 4.607 & 6.329 & 3 & 1 \\
\hline 14 & 616.27 & 302.13 & 1.513 & 4.453 & 7.800 & 3 & 1 \\
\hline
\end{tabular}


Table 3. Polarizabilities and magnetizabilities of compounds I-14 computed at the BLYP/TZP level of theory.

\begin{tabular}{ccc}
\hline Ligands & Polarizability/a.u. & Magnetizability / a.u. \\
\hline 1 & 269.73 & -714.75 \\
11 & 246.64 & -368.05 \\
12 & 248.59 & -390.53 \\
13 & 259.19 & -660.73 \\
14 & 285.36 & -705.30 \\
\hline
\end{tabular}

accessible area and magnetizability. For the ligand 13, removal of the chlorine from the benzene ring and replacement of $\mathrm{COOH}$ group with $\mathrm{CONH}_{2}$ leads to a lowering of the hydrophobic character. The replacement of the chlorine atom with thiomethyl does not influence the overall hydrophobicity of 14 ligand. According to the results depicted in Table 3, the absence of a substituent on the phenyl cycle results in the lower values of the solvent accessible surface and magnetizability.

\section{Docking Studies}

A number of 13 compounds within the class of rhombellanes have been considered for evaluating their interactions with indomethacin and its analogues, in order to evaluate their possible use as drug delivery systems. For comparison, fullerene $C_{60}$ has been employed as reference compound. Their structure specification is presented in table below (all the structures are depicted in the Supplementary Material).
Table 4. Polarizabilities and magnetizabilities of compounds I-I4 computed at the BLYP/TZP level of theory.

\begin{tabular}{cc}
\hline Compounds & Structure specification \\
\hline Ada-rbl.240 & $5:(6(6) \cdot \mathrm{B}(3) \cdot(2) \cdot 0)$ \\
Ada-rbl.276 & $5:(6(6) \cdot \mathrm{B}(3) \cdot \mathrm{Mt}(2) \cdot 0)$ \\
Ada-rbl.300 & $5:(6(6) \cdot 6(3) \cdot \mathrm{Mt}(2) \cdot 0)$ \\
C-rbl.348 & 7:(6(6).B(3).Mt(2).8B(3)) \\
C-rbl.360 & 7:6(6).6(6).Mt(2).8B(3)) \\
C-rbl.420 & 7:(6(6).B(3).Mt(2).8BMt(3)) \\
Core (ether).108 & $4:(6(3) \cdot \mathrm{B}(3) \cdot 0.0)$ \\
Core (ether).120 & $4:(6(6) \cdot \mathrm{B}(3) \cdot 0.0)$ \\
Core (ether.B).132 & $4:(6(3) \cdot 6(3) \cdot 0.0)$ \\
Core (amine).156 & $4:(6(6) \cdot 6(3) \cdot 0.0)$ \\
Core (amine).168 & $4:(6(6) \cdot 6(6) \cdot 0.0)$ \\
Core (ether).132 & $4:(6(6) \cdot \mathrm{B}(3) \cdot 0.0)$ \\
Core (ether).144 & $4:(6(6) \cdot 6(3) \cdot 0.0)$ \\
C60 & - \\
\hline
\end{tabular}

As in the case of the investigated ligands, a short evaluation of their global properties has been performed. The results depicted in Table 5 include the computed HOMO-LUMO gap and dipole moment; $\mathrm{HL}$ gaps less than or equal to $2 \mathrm{eV}$ have been obtained for C-rbl.348, C-rbl.360, Ada-rbl.240, Ada-rbl.300, Core (ether.B). 132 and $C_{60}$.

The results of the best binding affinities (Table 6; best binding affinities- bold, second best binding affinities-

Table 5. Polarizabilities and magnetizabilities of compounds I-14 computed at the BLYP/TZP level of theory.

\begin{tabular}{|c|c|c|c|c|}
\hline Compounds & $E_{\text {номо } / \mathrm{eV}}$ & $E_{\text {Lumo } / \mathrm{eV}}$ & HOMO-LUMO gap / eV & Dipole moment / D \\
\hline Ada-rbl.240 & -6.038 & -4.099 & 1.939 & 2.612 \\
\hline Ada-rbl.276 & -7.670 & -4.866 & 2.804 & 0 \\
\hline Ada-rbl.300 & -5.230 & -3.226 & 2.004 & 7.201 \\
\hline C-rbl.348 & -6.038 & -4.613 & 1.425 & 0.040 \\
\hline C-rbl.360 & -6.555 & -5.151 & 1.404 & 2.875 \\
\hline C-rbl.420 & -6.310 & -3.530 & 2.780 & 0 \\
\hline Core (ether).108 & -6.174 & -2.013 & 4.161 & 0.020 \\
\hline Core (ether).120 & -5.386 & -1.931 & 2.518 & 1.674 \\
\hline Core (ether.B).132 & -3.781 & -1.332 & 1.518 & 0.935 \\
\hline Core (amine).156 & -4.515 & -1.224 & 3.291 & 3.831 \\
\hline Core (amine).168 & -4.515 & -1.414 & 3.101 & 2.890 \\
\hline Core (ether). 132 & -5.630 & -1.958 & 3.672 & 0.014 \\
\hline Core (ether). 144 & -5.483 & -1.719 & 3.764 & 5.398 \\
\hline $\mathrm{C}_{60}$ & -5.630 & -4.053 & 1.577 & 0 \\
\hline
\end{tabular}


italic) outline that very close or equal values to the one corresponding to fullerene $\mathrm{C} 60$ have been obtained both for all the C-rbl derivatives and Ada-rbl.240. The abovementioned structures are characterized by smaller HOMOLUMO gaps (only C-rbl.420 has a HL gap higher than $2 \mathrm{eV}$, namely $2.78 \mathrm{eV}$ ). The influence of the HOMO-LUMO gap is outlined by the docking results of the structures with 108144 atoms; the highest binding affinity among them is attributed to Core (ether.B).132, which also has the lowest HL gap $(1.518 \mathrm{eV})$ within the group.

Table 6. The final Lamarckian genetic algorithm docked state - best binding affinities of ligands with the nanostructures (kcal mol-1).(a)

\begin{tabular}{|c|c|c|c|c|c|}
\hline \multicolumn{6}{|c|}{ The best binding affinity / $\mathrm{kcal} \mathrm{mol}^{-1}$} \\
\hline Compounds & । & 11 & 12 & 13 & 14 \\
\hline Ada-rbl.240 & -4.6 & -4.7 & -5.2 & -5.1 & -4.8 \\
\hline Ada-rbl.276 & -4.7 & -4.5 & -4.7 & -4.6 & -4.5 \\
\hline Ada-rbl.300 & -4.7 & -4.6 & -4.7 & -4.8 & -4.5 \\
\hline C-rbl.348 & -5.0 & -4.7 & -5.0 & -5.1 & -5.0 \\
\hline C-rbl.360 & -5.1 & -4.8 & -5.0 & -5.0 & -4.9 \\
\hline C-rbl.420 & -5.0 & -4.8 & -5.1 & -5.0 & -5.2 \\
\hline Core (ether).108 & -3.5 & -3.4 & -3.5 & -3.5 & -3.3 \\
\hline Core (ether). 120 & -3.7 & -3.6 & -3.8 & -3.8 & -3.8 \\
\hline Core (ether.B).132 & -4.3 & -4.1 & -4.4 & -4.4 & -4.2 \\
\hline Core (amine).156 & -3.4 & -3.3 & -3.4 & -3.4 & -3.4 \\
\hline Core (amine). 168 & -3.4 & -3.3 & -3.3 & -3.4 & -3.3 \\
\hline Core (ether).132 & -3.1 & -3.1 & -3.2 & -3.1 & -3.1 \\
\hline Core (ether).144 & -3.4 & -3.3 & -3.6 & -3.5 & -3.4 \\
\hline $\mathrm{C}_{60}$ & -5.7 & -5.0 & -5.4 & -5.5 & -5.2 \\
\hline
\end{tabular}

Table 7. Binding affinity ratio relative to ligand-fullerene $C_{60}$ and calculated constant binding balance $K_{\mathrm{B}}$.

\begin{tabular}{ccccccccccc}
\hline & \multicolumn{3}{c}{ Binding affinity rhombellanes/Binding affinity $C_{60}$} & \multicolumn{5}{c}{$K_{B}$ (constant binding balance) } \\
\hline & I & 11 & 12 & 13 & 14 & I & 11 & 12 & 13 & 14 \\
\hline Ada-rbl.240 & 0.81 & 0.94 & 0.96 & 0.93 & 0.92 & 2364.3 & 2799.3 & 6512.6 & 5500.7 & 3314.3 \\
Ada-rbl.276 & 0.82 & 0.90 & 0.87 & 0.84 & 0.86 & 2799.3 & 1996.9 & 2799.3 & 2364.3 & 1996.9 \\
Ada-rbl.300 & 0.82 & 0.92 & 0.87 & 0.87 & 0.86 & 2799.3 & 2364.3 & 2799.3 & 3314.3 & 1996.9 \\
C-rbl.348 & 0.88 & 0.94 & 0.93 & 0.93 & 0.96 & 4645.9 & 2799.3 & 4645.9 & 5500.7 & 4645.9 \\
C-rbl.360 & 0.89 & 0.96 & 0.93 & 0.91 & 0.94 & 5500.7 & 3314.3 & 4645.9 & 4645.9 & 3924.0 \\
C-rbl.420 & 0.88 & 0.96 & 0.94 & 0.91 & 1 & 4645.9 & 3314.3 & 5500.7 & 4645.9 & 6512.6 \\
Core (ether).108 & 0.61 & 0.68 & 0.65 & 0.64 & 0.63 & 368.9 & 311.6 & 368.9 & 368.9 & 263.2 \\
Core (ether).120 & 0.65 & 0.72 & 0.70 & 0.69 & 0.73 & 517.2 & 436.8 & 612.3 & 612.3 & 612.3 \\
Core (ether.B).132 & 0.75 & 0.82 & 0.81 & 0.80 & 0.81 & 1424.6 & 1016.2 & 1686.6 & 1686.6 & 1203.2 \\
Core (amine).156 & 0.60 & 0.66 & 0.63 & 0.62 & 0.65 & 311.6 & 263.2 & 311.6 & 311.6 & 311.6 \\
Core (amine).168 & 0.60 & 0.66 & 0.61 & 0.62 & 0.63 & 311.6 & 263.2 & 263.2 & 311.6 & 263.2 \\
Core (ether).132 & 0.54 & 0.62 & 0.59 & 0.56 & 0.60 & 187.7 & 187.7 & 222.3 & 187.7 & 187.7 \\
Core (ether).144 & 0.60 & 0.66 & 0.66 & 0.64 & 0.63 & 311.6 & 263.2 & 436.8 & 368.9 & 311.6 \\
C60 & 1 & 1 & 1 & 1 & 1 & 15151.8 & 4645.9 & 9129.3 & 10808.9 & 6512.6 \\
\hline
\end{tabular}


Due to the fact that the calculated values of the HOMO-LUMO gaps are influenced by the chosen method and basis set, ${ }^{[31,32]}$ another computation at the PBE/TZP level of theory has been performed. The results are depicted in the Supplementary File (see Table S6) and it can be seen that the small differences have no influence on the HL gap hierarchy within the present group of nanostructures.

Among the investigated rhombellanes, indomethacin and its analogues show the highest affinity towards the rhombellanes with an increased number of atoms (240, 348,360 and 420). The analysis of the docking results outlines that the main interactions are the stacking interactions between the aromatic moieties of the ligands and rhombellanes. Two hydrogen bonds are formed, one between the $\mathrm{NH}_{2}$ group of $\mathrm{I} 2$ analogue and the carbonyl group of nanostructure Ada_rbl.240, while the second hydrogen bond is established between the amino group of the nanomaterial and the carbonyl group of the ligand 13 .

Table 7 depicts the ratio of binding affinities (rhombellanes):binding affinity $\left(\mathrm{C}_{60}\right)$ and the constant binding values; the larger values suggest an increased binding affinity and sustain the results presented in Table 6 .

\section{CONCLUSIONS}

A docking study of five ligands (indomethacin and four derivatives) on 13 new structures within the class of rhombellanes has been performed, aiming to determine the possible use of the rhombellanes as drug carriers. According to the computed binding affinities for ligand-rhombellane complexes, there are four structures that gave similar results to the ones obtained for the reference ligand-fullerene $C_{60}$ complex. For the first ligand, indomethacin, the highest ratio rhombellane $/ C_{60}$ is 0.89 and is attributed to C-rbl.360. As regards the second ligand (derivative I1), an improved ratio of 0.96 has been obtained both for C-rbl.360 and C-rbl.420. Ada-rbl.240 gave the best binding affinity for ligands 12 and 13 (0.96 and 0.93, respectively), while the complex C-rbl.42014 has an equal binding affinity to the $\mathrm{C}_{60}-14$ complex.

The results suggest that the rhombellane structures that are characterized by a smaller HOMO-LUMO gap are the most favored for higher binding affinity values to the indomethacin derivatives.

Acknowledgment. This work is supported by the Slovenian Research Agency project grants J1-1715, Protein interaction atlas for prediction of genetic variations involved in drug interactions and disease development (D.J.); J1-9186, New computational tools at the PDB scale for drug discovery.

Supplementary Information. Supporting information to the paper is attached to the electronic version of the article at: https://doi.org/10.5562/cca3591.
PDF files with attached documents are best viewed with Adobe Acrobat Reader which is free and can be downloaded from Adobe's web site.

\section{REFERENCES}

[1] J. M. Alvaro-Garcia, Rheumatology 2004, 43, 121125. https://doi.org/10.1093/rheumatology/keh105

[2] A. A. Onischuk, T. G. Tolstikova, S. V. An'kov, A. M. Baklanov, S. V. Valiulin, M. V. Khvostov, V. Sorokina, G. G. Dultseva, N. A. Zhukova, J. Aerosol Sci. 2016, 100, 164-177.

https://doi.org/10.1016/j.jaerosci.2016.05.005

[3] M. Boehme, M. Guenther, A. Stahr, M. Liebmann, N. Jaenisch, O. W. Witte, C. Frahm, Neurosci. Lett. 2014, 572, 7-12. https://doi.org/10.1016/j.neulet.2014.04.043

[4] S. Chennamaneni, C. Gan, R. Lama, B. Zhong, B. Su, Bioorg. Med. Chem. 2016, 24, 277-285.

https://doi.org/10.1016/j.bmc.2015.12.016

[5] S. Yokoe, T. Nakagawa, Y. Kojima, M. Asahi, Biochem. Biophys. Res. Commun. 2015, 468, 671-676. https://doi.org/10.1016/j.bbrc.2015.11.014

[6] A. S. Nagappan, J. Varghese, J. V. James, M. Jacob, Eur. J. Pharmacol. 2015, 761, 199-205. https://doi.org/10.1016/j.ejphar.2015.04.044

[7] H. M. Badawi, W. Förner. Spectrochim, Acta A: Mol. Biomol. Spectrosc. 2014, 123, 447-454. https://doi.org/10.1016/j.saa.2013.12.044

[8] M. B. Labib, S.M.Z. Sharkawi, M. El-Daly, Bioorg. Chem. 2018, 80, 70-80. https://doi.org/10.1016/j.bioorg.2018.05.018

[9] S. E. Kassab, M. A. Khedr, H. I. Ali, M. M. Abdalla, Eur. J. Med. Chem. 2017, 141, 306-321. https://doi.org/10.1016/j.ejmech.2017.09.056

[10] A. D. T. Moraes, M. D. Santos de Miranda, I. T. T. Jacob et al, Bioorg. Med. Chem. 2018, 26, 5388.

[11] Y. Zhou, Pharmaceutics 2013, 5, 525-541. https://doi.org/10.3390/pharmaceutics5040525

[12] M. Kia, M. Golzar, K. Mahjoub, A. Soltani, Superlattices Microstruct. 2013, 62, 251-259. https://doi.org/10.1016/j.spmi.2013.07.010

[13] S. Syama, P. V. Mohanan, Int. J. Biol. Macromol. 2016, 86, 546-555.

https://doi.org/10.1016/j.ijbiomac.2016.01.116

[14] M. V. Diudea, Iranian J. Math. Chem. 2018, 9, 1-9.

[15] B. Szefler, P. Czelen, M.V. Diudea, STUDIA UBB Chemia 2018, LXIII(2), 7-18.

https://doi.org/10.24193/subbchem.2018.2.01

[16] A. R. Maguire, S. J. Plunkett, S. Papot, M. Clynes, R. O'Connor, S. Touhey, Bioorg. Med. Chem. 2001, 9, 745-762.

https://doi.org/10.1016/S0968-0896(00)00292-3

[17] A. M. Harsa, T. E. Harsa, M. V. Diudea, D. Janezic, Curr. Comput. Aided Drug Des. 2015, 11, 353-360. https://doi.org/10.2174/1874609809666151223093040 
[18] S. Lešnik, J. Konc, D. Janežič, Croat. Chem. Acta 2016, 89, 431-437.

https://doi.org/10.5562/cca2993

[19] T. E. Harsa, A. M. Harsa, B. Szefler, M. V. Diudea, Croat. Chem. Acta 2016, 89, 17-24.

https://doi.org/10.5562/cca2733

[20] C. T. Zeyrek., H. Ünver, B.Boyacioglu, N. Demir, G.Yapar, H. Dal, M. Yıldı, Croat. Chem. Acta 2018, 91, 341. https://doi.org/10.5562/cca3316

[21] O. Trott, A. J. Olson, J. Comput. Chem. 2010, 31, 455-461.

https://doi.org/2010.1002/jcc.21334

[22] S. J. A. van Gisbergen, J. G. Snijders, E. J. Baerends, J. Chem. Phys. 1995, 103, 9347. https://doi.org/10.1063/1.469994

[23] S. J. A. van Gisbergen, J. G. Snijders, E. J. Baerends, Comp. Phys. Commun. 1999, 118, 119-138. https://doi.org/10.1016/S0010-4655(99)00187-3

[24] M. Krykunov, J. Autschbach, J. Chem. Phys. 2007, 126, 24101.

https://doi.org/10.1063/1.2423007
[25] G. te Velde, F. M. Bickelhaupt, E. J. Baerends. C. Fonseca Guerra, S. J. A. van Gisbergen, J. G. Snijders, T. Ziegler, J. Comput. Chem. 2001, 22, 931-967. https://doi.org/10.1002/jcc.1056

[26] C. Fonseca Guerra, J. G. Snijders, G. te Velde, E. J. Baerends, Theor. Chem. Acc. 1998, 99, 391-403. https://doi.org/10.1007/s002140050021

[27] ADF2014, SCM, Theoretical Chemistry, Vrije Universiteit, Amsterdam, The Netherlands, http://www.scm.com

[28] E. van Lenthe, E. J. Baerends, J. Comput. Chem. 2003, 24, 1142-1156. https://doi.org/10.1002/jcc.10255

[29] Y. Zyrianov, J. Chem. Inf. Model. 2005, 45, 657-672. https://doi.org/10.1021/ci050005।

[30] T. Lu, F.J. Chen, J. Comput. Chem. 2012, 33, 580-592. https://doi.org/10.1002/jcc. 22885

[31] C. B. R. Santos, C. C. Lobato, F. S. Braga et al., Comput. Mol. Biosci. 2014, 4, 1-24. https://doi.org/10.4236/cmb.2014.41001

[32] S. McKechnie, G. H. Booth, A. J. Cohen, J. M. Cole, J. Chem. Phys. 2015, 142, 194114.

https://doi.org/10.1063/1.4921037 